\title{
ANALISIS PERAN CUSTOMER SERVICE DI BANK BNI SYARIAH KCP PLERED
}

\author{
Joni $^{1}$, Fikri Putri Diniati ${ }^{2}$ \\ ${ }^{1}$ Program Studi Ekonomi Syariah Universitas Siliwangi, joni@unsil.ac.id \\ ${ }^{2}$ Program Studi Ekonomi Syariah Universitas Siliwangi, fikridiniati@gmail.com
}

\begin{abstract}
Customer service plays a very important role in various companies and financial institutions such as Islamic banks. As a Customer Service, the roles and functions must be established. If customer service does not implement one of the functions that should be carried out, it will have an impact on the role of customer service, namely maintaining customers and getting new customers. The role of customer service can be carried out if each of the functions can be implemented by customer service. The purpose of this study was to determine the role of Customer Service at Bank BNI Syariah KCP Plered.The method used in this study is a descriptive method with is qualitative. With two data sources, namely primary data sources consisting of Customer Service, Operational Service Head, several customer security guards and secondary data sources consisting of supporting books, working papers and photos obtained from the field. Data collection techniques used were interviews, observation and documentation. Based on the results research that role customer service at Bank BNI Syariah $K C P$ Plered that is customer service as a service unit able to doing its role that is maintain customer and get customer new in the counter or bank. Implementation role could seen from implementation every the functions contained inside, though there is some functions that are not yet optimal in implementation .
\end{abstract}

Keyword: Sharia Bank, Role of Customer Service, Customer Service Function .

\begin{abstract}
ABSTRAK
Customer service memegang peranan sangat penting diberbagai perusahaan maupun lembaga keuangan seperti bank syariah. Sebagai seorang Customer Service tentu telah ditetapkan peran dan fungsi yang harus diembannya. Apabila customer service tidak mengimplementasikan salah satu fungsi yang seharusnya dilaksanakan, maka akan berdampak pada peran customer service yaitu mempertahankan nasabah dan mendapatkan nasabah baru. Tujuan penelitian ini untuk mengetahui Peran Customer Service di Bank BNI Syariah KCP Plered. Metode yang digunakan dalam penelitian ini adalah metode deskriptif dengan pendekatan kualitatif. Dengan dua sumber data yaitu sumber data primer yang terdiri dari Customer Service, Operational Service Head, Satpam beberapa nasabah dan sumber data sekunder yang terdiri dari buku pendukung, kertas kerja maupun foto yang didapat dari lapangan. Teknik pengumpulan data yang digunakan adalah wawancara, observasi dan dokumentasi. Berdasarkan hasil penelitian bahwa peran customer service di Bank BNI Syariah KCP Plered yaitu customer service sebagai unit layanan mampu melaksanakan perannya yaitu mempertahankan nasabah dan mendapatkan nasabah baru di dalam counter atau bank.
\end{abstract}


Pelaksanaan peran ini dapat dilihat dari pengimplementasian setiap fungsi yang terkandung didalamnya,meskipun ada beberapa fungsi yang belum optimal dalam pengimplementasiannya.

Kata Kunci: Bank Syariah, Peran Customer Service, Fungsi Customer Service.

\section{PENDAHULUAN}

Semakin banyak dan berkembangnya bank syariah di Indonesia seperti Bank Muamalat Indonesia, Bank Mandiri Syariah, BNI Syariah, BJB Syariah, BTN Syariah, BRI Syariah dan lain sebagainya, maka setiap bank syariah harus mempunyai sesuatu yang menjadi keunggulan bank syariah untuk menarik perhatian calon nasabah maupun nasabah agar tetap menggunakan bank syariah tersebut. Salah catu caranya dengan kualitas pelayanan melalui Customer Service.

Menurut Kasmir (2017), secara umum pengertian customer service adalah setiap kegiatan yang diperuntukkan atau ditujukan kepada seseorang untuk memberikan kepuasan kepada pihak nasabah melalui pelayanan dapat memenuhi keinginan dan kebutuhan nasabah. Secara umum peranan customer service lembaga keuangan yaitu berusaha mempertahankan nasabah dan berusaha mendapat nasabah baru. Sebagai seorang Customer Service tentu telah ditetapkan fungsi yang harus diembannya. Customer Service juga bertanggung jawab dari awal sampai selesainya pelayanan nasabah. Fungsi customer service harus benar-benar dipahami sehingga dapat menjalankan tugasnya secara prima.

Menurut Kasmir (2017), fungsi dan peran customer service ini harus dilakukan secara bersama-sama menjadi satu kesatuan. Artinya tidak boleh hanya dilakukan salah satu dari fungsi tersebut atau tidak lengkap, karena masing-masing fungsi saling melengkapi. Seorang customer service dituntut untuk memahami dan melaksanakan seluruh fungsi dan peran yang diembannya dengan sebaik-baiknya.

Pada kenyataannya, fungsi customer service belum sepenuhnya dapat dijalankan dengan baik dikarenakan beberapa permasalahan-permasalahan yang dihadapi oleh customer service itu sendiri maupun nasabah. Permasalahan-permasalahan customer service di Bank BNI Syariah KCP Plered tersebut meliputi komplain nasabah, kurangnya pemahaman customer service dan nasabah terhadap produk dan akad, kurangnya pemahaman nasabah dalam melengkapi pengisian form/ aplikasi serta persyaratan yang harus dibawa, dan lain sebagainya.

Apabila salah satu fungsi customer service saja tidak di implementasikan apa yang sudah menjadi fungsi yang seharusnya dijalankan maka peran customer service tidak akan berjalan dengan sepenuhnya. Peran customer service akan bisa berjalan sepenuhnya apabila setiap fungsi customer servive bisa di implementasikan dengan baik.

Bank BNI Syariah Kantor Cabang Pembantu Plered merupakan lembaga keuangan bank yang mempunyai visi :" menjadi bank syariah pilihan masyarakat yang unggul dalam layanan dan kinerja." Dalam visi tersebut jelas mengedepankan dalam layanan dan kinerja yang diharapkan dalam mengimplementasikan layanan yang baik khususnya customer service akan meningkatkan kinerja dari Bank BNI Syariah itu sendiri. 


\section{LITERATUR REVIEW}

\section{Bank Syariah}

Menurut Akhmad Mujahidin (2016), Bank Syariah adalah suatu lembaga keuangan yang berfungsi sebagai perantara bagi pihak yang berkelebihan dana dengan pihak yang kekurangan dana untuk kegiatan usaha dan kegiatan lainnya sesuai dengan hukum Islam. Selain itu, bank syariah juga berfungsi sebagai manajer investasi dan investor.

\section{Peran Customer Service}

Menurut Kasmir (2005), Customer service memegang peranan sangat penting diberbagai perusahaan. Dalam dunia perbankan, tugas utama seorang customer service adalah memberikan pelayanan dan membina hubungan dengan masyarakat. Customer service bank dalam melayani para nasabah selalu berusaha menarik dengan cara meyakinkan para calon nasabah agar menjadi nasabah bank yang bersangkutan dengan berbagai cara. Selain itu customer service juga harus dapat menjaga nasabah lama agar tetap menjadi nasabah bank.

Secara umum, peranan customer service bank adalah:

1) Berusaha Mempertahankan Nasabah

Mempertahankan nasabah lama agar tetap setia menjadi nasabah bank melalui pembinaan hubungan yang lebih akrab dengan nasabah. Ini juga ditunjukan oleh pelayanan yang lebih baik sehingga nasabah lama dipengaruhi untuk menambah jumlah transaksinya. Peran customer service untuk mempertahankan nasabah meliputi fungsi resepsionis, fungsi deskman, fungsi customer relation officer, dan fungsi penanganan masalah.

2) Berusaha Mendapat Nasabah Baru

Berusaha untuk mendapat nasabah baru, melalui berbagai pendekatan. Misalnya, meyakinkan nasabah tentang kualitas produk kita. Dengan cara merayu nasabah yang baru datang pertama kali untuk menjadi nasabah kita seterusnya dan meyakinkan nasabah baru tentang kualitas produk yang kita tawarkan dan tunjukan dengan layanan terbaiknya, sehingga nasabah merasa yakin dan memutuskan menjadi nasabah baru. Peran customer service untuk mendapatkan nasabah baru meliputi fungsi salesman dan fungsi komunikator.

Menurut Kasmir (2005), fungsi dan peran customer service ini harus dilakukan secara bersama-sama menjadi satu kesatuan. Artinya tidak boleh hanya dilakukan salah satu dari fungsi tersebut atau tidak lengkap, karena masing-masing fungsi saling melengkapi. Seorang customer service dituntut untuk memahami dan melaksanakan seluruh fungsi dan peran yang diembannya dengan sebaik-baiknya.

\section{Fungsi Customer Service}

1) Sebagai Resepsionis

Resepsionis adalah orang yang bertugas sebagai penerima tamu, dalam Kamus Besar Bahasa Indonesia Pusat Bahasa, Customer service bertugas sebagai resepsionis yaitu 
sebagai penerima tamu yang datang ke bank. Tamu yang dimaksud adalah nasabah yang datang ke bank. Fungsinya dalam hal ini adalah melayani pertanyaan-pertanyaan yang diajukan oleh nasabah dan memberikan informasi yang diinginkan selengkap mungkin.

Menurut Sugiarto yang dikutip oleh Drie Rona Maiziva (2017), mengatakan bahwa seorang resepsionis sebagai front office harus mempunyai peranan sebagai berikut:
a. Diplomatic Agent
b. RecordKeeper
c. InformationSource
d. Psychologist
e. Sales Person

2) Sebagai Deskman

Menurut Kasmir (2017), Sebagai deskman artinya seorang customer service berfungsi sebagai orang yang melayani berbagai macam aplikasi yang diajukan nasabah dan calon nasabah. Pelayanan yang diberikan termasuk memberikan arahan dan petunjuk cara-cara pengisian aplikasi tersebut hingga tuntas, serta prosedur yang diinginkan. Artinya, jika nasabah sudah memperoleh informasi secara lengkap kemudian bermaksud melakukan transaksi, petugas customer service melayani nasabah untuk mengisi berbagai aplikasi seperti formulir, slip atau lainnya.

Menurut Ikatan Bankir Indonesia(IBI), Customer service sebagai fungsi deskman yaitu melayani pembukaan, pemeliharaan, dan penutupan rekening yang mempunyai indikator sebagai berikut:

a. Menerima permohonan pembukaan/pengkinian data nasabah/penutupan rekening, serta pemberian/pencabutan fasilitas.

b. Memeriksa kelengkapan dan kebenaran pengisian formulir

c. Mengadministrasikan data customer dan pembukaan rekening.

d. Menyerahkan bukti kepemilikan rekening, kartu yang terkait dengan rekening, bilyet deposito kepada nasabah.

e. Menerima permintaan pembayaran bunga deposito.

f. Melakukan aktivasi PIN dari kartu yang terkait dengan rekening dan telah diserahterimakan dengan nasabah.

\section{3) Sebagai Salesman}

Customer service berfungsi sebagai orang yang menjual produk perbankan sekaligus sebagi pelaksana cross selling. Menjual produk artinya menawarkan produk bank kepada setiap calon nasabah yang datang ke bank. Dalam hal ini customer service harus pandai menyakinkan nasabah agar mau membeli produk yang ditawarkan.

Adapun beberapa hal yang harus dikuasai oleh tenaga penjual atau sales person, sebagai berikut :

a. Product Knowledge 


\section{b. Price Policy \\ c. Human Relation}

4) Sebagai Customer Relation Officer

Customer Relation Officer yaitu berfungsi sebagai orang yang dapat membina hubungan baik dengan seluruh nasabah, termasuk merayu atau membujuk agar nasabah tetap bertahan tidak lari dari bank yang bersangkutan apabila menghadapi masalah. Fungsi sebagai Customer Relation Officer dapat dilakukan dengan berbagai cara, misalnya komunikasi melalui telepon atau secara langsung.

Implementasi Customer Relation Management (CRM) setidaknya harus memiliki elemen-elemen berikut:

a. Otomatisasi pemasaran

b. Pusat pelayanan (call center)

c. Penggudangan data (data warehousing)

5) Sebagai Komunikator

Customer service adalah satu-satunya personil yang dengan mudah dihubungi oleh nasabah pada kesempatan pertama, maka petugas customer service menjadi pusat dan narasumber informasi-informasi mengenai produk dan jasa bank, kurs transaksi, tingkat suku bunga yang berlaku hari ini, biaya administrasi dan lain-lain. Oleh karenanya dituntut personil yang mempunyai pengetahuan dan wawasan yang cukup baik mengenai industri perbankan. Menurut Ikatan Bankir Indonesia(IBI).

Menurut Herry Sutanto (2013), dalam penyampaian informasi, seorang komunikator harus memiliki indikator-indikator sebagai berikut:

a. Merancang isi pesan,

b. Memilih saluran (Media) Komunikasi/Promosi.

6) Penanganan Masalah

Unit customer service apabila dalam operasionalnya, nasabah tidak puas, karena terdapat ketidakcocokkan atau kesepakatan, komplain dan lain-lain sebagainya, maka adalah tepat apabila orang pertama yang dihubungi adalah petugas customer service. Dalam hal ini dituntut tidak saja dapat menangani keluhan akan tetapi juga diharapkan dapat memecahkan masalah dengan baik sebagai "troubleshooter".

Menurut Kasmir (2017), customer service sebagai fungsi penanganan masalah/handling complain yaitu memberikan pelayanan keluhan dan pelayanan solusi yang mempunyai indikator sebagai berikut:

a. Pelayanan Keluhan

Menerima keluhan nasabah,mencatat/mengadministrasikan, meneruskan, dan memonitor ke unit kerja terkait, serta menginformasikan penyelesaian keluhan ke nasabah. 
b. Pelayanan Solusi

1) Menggali kebutuhan nasabah/calon nasabah

2) Memberikan informasi tentang solusi/layanan kebutuhan nasabah/calon nasabah melalui:

3) Meneruskan kebutuhan kredit atau investasi kepada unit terkait dengan memastikan proses layanan nasabah berjalan baik

4) Memproses layanan bisnis non kredit, baik secara langsung maupun melalui unit lainnya

5) Memproses permintaan produk/layanan sesuai dengan kebutuhan nasabah, sesuai dengan service level yang ada/janji kepada nasabah.

6) Meneruskan dan memastikan proses permintaan produk/ layanan nasabah ke unit terkait sesuai dengan service level yang ada/janji kepada nasabah.

7) Melayani permintaan/keluhan nasabah dan aktif menginformasikan nasabah atau unit lain mengenai update status/solusi.

8) Mencarikan alternatif solusi atau melakukan eskalasi atas masalah yang belum bisa diselesaikan serta memastikan bahwa masalah tersebut ditindaklanjuti sampai tuntas.

9) Membuat referensi dan konfirmasi saldo berdasarkan permohonan dari nasabah.

\section{METODE}

Metode Penelitian

Dalam penelitian ini menggunakan metode penelitian deskriptif dengan pendekatan kualitatif, dengan melakukan Analisis Peran Customer Service di Bank BNI Syariah KCP Plered.

Sumber Data

Data primer terdiri dari OSH, Customer Service, Satpam, Beberapa nasabah dan Kertas Kerja di Bank BNI Syariah KCP Plered. Sedangkan data sekunder terdiri dari buku-buku mengenai bank syariah dan customer service atau yang setema dengan judul.

Teknik Pengumpulan Data

Penelitian ini menggunakan observasi, wawancara dan dokumentasi.

Instrumen Penelitian

Dalam penelitian ini, peneliti menggunakan 2 instrumen yaitu, dirinya sendiri sebagai instrumen dan pedoman wawancara sebagai pedoman untuk melakukan wawancara.

Uji Kredibilitas Data

Adapun uji kredibilitas data yang dilakukan peneliti dalam penelitian ini yaitu dengan triangulasi sumber dan triangulasi teknik. Serta kecukupan bahan referensi.

Teknik Analis Data

Dalam menganalisis data, penelitian ini menggunakan data reduction, data display, dan conclusion drawing. 


\section{HASIL DAN PEMBAHASAN}

\section{Analisis Peran Customer Service di Bank BNI Syariah KCP Plered}

1. Mempertahankan Nasabah

Analisis penulis terkait dengan peran customer service yaitu sebagai unit layanan mempunyai peran yaitu mempertahankan nasabah oleh customer service dan funding. Akan tetapi customer service mempunyai cara seperti memilih nasabah-nasabah prioritas untuk menawarkan produk lain/terbaru yang ada di Bank BNI Syariah KCP Plered dan apabila ada nasabah yang akan melakukan penarikan dalam jumlah besar ditanyakan terlebih dahulu yang bertujuan supaya nasabah tetap menggunakan Bank BNI Syariah KCP Plered. Peran ini dapat dilaksanakan apabila fungsi dari customer service dilaksanakan oleh customer service. Peran customer service untuk mempertahankan nasabah meliputi fungsi resepsionis, fungsi deskman, fungsi customer relation officer, dan fungsi penanganan masalah. Untuk fungsi resepsionis sendiri merupakan fungsi dari frontliner bukan hanya fungsi dari customer service, fungsi deskman belum optimal pada bagian pengecekan kelengkapan data nasabah pada formulir/aplikasi, fungsi customer relation officer sudah optimal karena customer service memberikan pelayanan yang bisa menjaga hubungan baik dengan nasabah supaya tetap bertahan, dan fungsi penanganan masalah sudah optimal karena customer service bisa menerima keluhan dan memberikan solusi kepada nasabah.

2. Mendapatkan Nasabah Baru

Analisis penulis terkait dengan peran ini yaitu untuk mendapatkan nasabah baru merupakan peran customer service dan funding. Customer service dalam hal mendapatkan nasabah baru yaitu walk in customer sebagai fungsi pemasar tetapi tinggal didalam counter. Nasabah datang sendiri ke bank untuk menjadi nasabah, akan tetapi jika diluar bank maka itu merupakan fungsi funding untuk mendapatkan nasabah. Untuk mendapatkan nasabah baru yang dilakukan customer service yaitu dengan melaksanakan fungsi salesman dan fungsi komunikator. Fungsi salesman sudah optimal dalam menawarkan terkait dengan produk dan akad secara langsung. Fungsi komunikator belum optimal karena hanya memberikan informasi terkait produk dan akad saja seharusnya bisa memberikan informasi apapun yang berkaitan dengan bank syariah secara langsung maupun tidak langsung.

\section{KESIMPULAN}

Customer service sebagai unit layanan mampu melaksanakan perannya yaitu mempertahankan nasabah dan mendapatkan nasabah baru didalam counter atau bank. Pelaksanaan peran ini dapat dilihat dari pengimplementasian setiap fungsi yang terkandung didalamnya, meskipun ada beberapa fungsi yang belum optimal dalam pengimplementasiannya

Adapun saran yang diberikan: untuk Akademisi; diharapkan peneliti selanjutnya bisa lebih memperdalam teori-teori tentang peran customer service, agar bisa menghasilkan informasi- 
informasi dari pihak perbankan maupun nasabah lebih rinci dan lebih jelas lagi, dan diharapkan peneliti selanjutnya bisa lebih mengembangkan penelitiannya. Untuk praktisi; Customer service juga harus memahami dan melaksanakan kertas kerja yang pada dasarnya didalamnya terdapat peran dan fungsi customer service karena apabila salah satu dari point kertas kerja tidak dilaksanakan nasabah akan kurang nyaman dan percaya pada bank syariah tersebut. Melakukan perbaikan dan pembaharuan mengenai layanan yang sesuai dengan kebutuhan nasabah.

\section{REFERENSI}

Cangara, Hafied. 2015. Pengantar Ilmu Komunikasi. Jakarta: PT Rajagrafindo Persada.

Ikatan Bankir Indonesia (IBI) dan Lembaga Sertifikasi Profesi Perbankan(LSPP). 2016. Mengelola Kualitas Layanan Perbankan. Jakarta: PT. Gramedia Pustaka Utama.

Kasmir. 2017. Customer Service Excellent. Jakarta: PT. Rajagrafindo Persada. . 2005. Etika Customer Service. Jakarta: Rajawali Press. . 2004. Pemasaran Bank. Jakarta: Prenada Media Group.

Mujahidin, Akhmad. 2016. Hukum Perbankan Syariah. Depok: PT Rajagrafindo Persada.

Nurudin. 2016. Ilmu Komunikasi. Depok: PT Rajagrafindo Persada.

Pusat Bahasa. 2015. Kamus Besar Bahasa Indonesia Pusat Bahasa. Jakarta: PT Gramedia Pustaka Utama.

Rivai Zainal, Veitzhal, dkk. 2017. Islamic Marketing Management. Jakarta: Bumi Aksara.

Sutanto, Herry dkk. 2013. Manajemen Pemasaran Bank Syariah. Bandung: CV Pustaka Setia.

Maiziva, Drie Rona. 2017. "Peranan Resepsionist pada Front Office Departement Hotel Grand Zuri Pekanbaru”. JOM FISIP. Vol.4 No. 2. Diakses dari https://media.neliti.comDiakses pada 8 Desember 2018 